\title{
Exertional dyspnoea in chronic heart failure: the role of the lung and respiratory mechanical factors
}

\author{
Bruno-Pierre Dubé ${ }^{1}$, Piergiuseppe Agostoni ${ }^{2,3}$ and Pierantonio Laveneziana ${ }^{4,5}$ \\ Number 1 in the Series “Exertional Dyspnoea” \\ Edited by Pierantonio Laveneziana and Piergiuseppe Agostoni
}

\begin{abstract}
Affiliations: ${ }^{1}$ Dépt de Médecine, Service de Pneumologie, Centre Hospitalier de l'Université de Montréal (CHUM), Montreal, QC, Canada. ${ }^{2}$ Centro Cardiologico Monzino, IRCCS, Milan, Italy. ${ }^{3}$ Dept of Clinical Sciences and Community Health, Cardiovascular Section, University of Milan, Milan, Italy. ${ }^{4}$ Sorbonne Universités, UPMC Université Paris 06, INSERM, UMRS 1158 Neurophysiologie respiratoire expérimentale et clinique, Paris, France. ${ }^{5}$ Assistance Publique-Hôpitaux de Paris, Groupe Hospitalier Pitié-Salpêtrière Charles Foix, Service des Explorations Fonctionnelles de la Respiration, de l'Exercice et de la Dyspnée (Département "R3S", Pôle PRAGUES), Paris, France.

Correspondence: Pierantonio Laveneziana, Service d'Explorations Fonctionnelles de la Respiration, de l'Exercice et de la Dyspnée, Département "R3S" (Respiration, Réanimation, Réhabilitation, Sommeil), Pôle PRAGUES, Hôpital Universitaire Pitié-Salpêtrière, Assistance Publique-Hôpitaux de Paris (AP-HP), 47-83 Boulevard de l'Hôpital, 75013, Paris, France. E-mail: pierantonio.lavenezianaApsl.aphp.fr
\end{abstract}

ABSTRACT Exertional dyspnoea is among the dominant symptoms in patients with chronic heart failure and progresses relentlessly as the disease advances, leading to reduced ability to function and engage in activities of daily living. Effective management of this disabling symptom awaits a better understanding of its underlying physiology.

Cardiovascular factors are believed to play a major role in dyspnoea in heart failure patients. However, despite pharmacological interventions, such as vasodilators or inotropes that improve central haemodynamics, patients with heart failure still complain of exertional dyspnoea. Clearly, dyspnoea is not determined by cardiac factors alone, but likely depends on complex, integrated cardio-pulmonary interactions.

A growing body of evidence suggests that excessively increased ventilatory demand and abnormal "restrictive" constraints on tidal volume expansion with development of critical mechanical limitation of ventilation, contribute to exertional dyspnoea in heart failure. This article will offer new insights into the pathophysiological mechanisms of exertional dyspnoea in patients with chronic heart failure by exploring the potential role of the various constituents of the physiological response to exercise and particularly the role of abnormal ventilatory and respiratory mechanics responses to exercise in the perception of dyspnoea in patients with heart failure.

@ERSpublications

In heart failure, respiratory and peripheral factors play a significant role in exertional dyspnoea development http://ow.ly/8oEN301w551

Editorial comment in Eur Respir Rev 2016; 25: 227-229.

Other articles in this series: No. 2: O’Donnell DE, Elbehairy AF, Faisal A, et al. Exertional dyspnoea in COPD: the clinical utility of cardiopulmonary exercise testing. Eur Respir Rev 2016; 25: 333-347.

Received: May 102016 | Accepted after revision: June 132016

Conflict of interest: Disclosures can be found alongside this article at err.ersjournals.com

Provenance: Submitted article, peer reviewed.

Copyright OERS 2016. ERR articles are open access and distributed under the terms of the Creative Commons Attribution Non-Commercial Licence 4.0. 


\section{Introduction}

Chronic heart failure is a common and disabling syndrome, currently affecting approximately 26 million people worldwide $[1,2]$. Despite optimal modern pharmacological treatment, many heart failure patients experience severe and persistent symptoms and their prognosis remains poor $[1,2]$. Exertional dyspnoea is among the dominant symptoms of patients with heart failure and progresses relentlessly as the disease advances, leading to reduced ability to function and engage in activities of daily living [3, 4]. Effective management of this disabling symptom awaits a better understanding of its underlying physiology.

The classic notion that exercise intolerance in heart failure is caused by the inability of the cardiac pump to support the increased metabolic demand of the exercising muscles (causing leg fatigue) and its inability to do so without abnormal increases in pulmonary venous pressures (causing dyspnoea) has been widely challenged by an increasing body of literature. It is now clear that symptom limitation is not determined by central haemodynamic factors alone, but likely depends on complex, integrated cardio-ventilatory, neurohumoral and peripheral factors.

A growing body of evidence suggests that excessively increased ventilatory demand and abnormal "restrictive" constraints on tidal volume $(V \mathrm{~T})$ expansion with development of critical mechanical limitation of ventilation, contribute to exertional dyspnoea in heart failure $[5,6]$. This contention has been bolstered by studies that have shown that pharmacological and non-pharmacological interventions capable of reducing the ventilatory response to exercise and/or improving the respiratory mechanics resulted in salutary sensory consequences for patients with heart failure [5-7].

This article will attempt to shed light on potential mechanisms underlying exertional dyspnoea in patients with heart failure by examining the potential role of the various constituents of the physiological response to exercise and particularly the role of abnormal ventilatory and respiratory mechanics responses to exercise in the perception of dyspnoea in patients with heart failure.

\section{The perception of exertional dyspnoea and leg fatigue in heart failure}

Patients with heart failure stop exercise because of either intolerable exertional dyspnoea, leg fatigue/ discomfort or both, at a point where there is apparent cardiopulmonary reserve $[3,8]$. Although studies conducted on large populations of patients with cardiorespiratory disorders have showed that leg discomfort is the most frequent exercise-limiting symptom in heart failure $[9,10]$, severe dyspnoea is also frequently reported $[5,6,9-11]$. The precise mechanisms underlying the choice, by a given patient with heart failure, to describe either dyspnoea or fatigue as their main limiting symptom remain unclear, but accumulating research tend to show that these two symptoms may, in fact, be inter-related [3].

In the general setting of peripheral muscle failure (either intrinsic or secondary to insufficient oxygen delivery), a greater central motor command output is required for a given contractile force generation [12, 13]. The accompanying increased central corollary discharge to the sensory cortex gives rise to a sense of increased contractile effort that can become intolerable if it exceeds a certain sensory threshold that will vary among individuals [12-15]. In addition, local alterations in the metabolic milieu due to excessive metabolite accumulation in the working muscles (as a result of metabolic derangements, reduced blood perfusion or both) may alter afferent inputs from multiple muscle mechanosensors (including pain sensors), which can project directly to the sensory cortex where they are perceived as an unpleasant sensation of leg discomfort $[3,15]$.

CLARK et al. [8] analysed data from 222 incremental symptom-limited exercise tests to determine whether there were differences between heart failure patients who stopped exercising because of dyspnoea or leg fatigue. They found that 160 patients stopped exercising because of dyspnoea whereas 62 were limited by leg fatigue and that there were no differences in underlying diagnosis, left ventricular haemodynamic performance, aerobic capacity (peak oxygen uptake (peak $\left.V^{\prime} \mathrm{O}_{2}\right)$ ) and ventilatory efficiency (evaluated using the slope of the relationship between minute ventilation $\left(V^{\prime} \mathrm{E}\right)$ and carbon dioxide production $\left(V^{\prime} \mathrm{CO}_{2}\right): V^{\prime} \mathrm{E} / V$ ' $\mathrm{CO}_{2}$ ). Similarly, another study evaluated 71 patients with heart failure during an incremental exercise test. While 41 patients stopped exercising because of dyspnoea and the remainder because of leg fatigue, no differences were observed in ventilatory and metabolic responses in both groups [11]. Of note, significant dyspnoea was also reported by the fatigue-limited group (mean Borg rating of 6.8). Although dynamic respiratory mechanics, operating lung volumes and the haemodynamic response to exercise were not directly assessed, these data suggest that, indeed, the factors influencing the respective determinants of the subjective reason for exercise termination in patients with heart failure cannot be easily inferred from accessible cardiac and ventilatory characteristics and, importantly, raise the question of whether these descriptors could be conceptualised as being two subjective manifestations of the same physiological phenomenon.

It should also be kept in mind, however, that the fact that some heart failure patients interpret their symptoms as dyspnoea while others as leg fatigue/discomfort may variably depend on the presence or absence of concomitant lung disease as well as on the type of exercise testing used. Exercise tests with a 
more rapid increment in workload are likely to be terminated by dyspnoea, whereas slower tests, although eliciting the same exercise performance, are more likely to be terminated by leg fatigue/discomfort [16]. Exercise modality must also be considered: when compared with treadmill exercise, cycling is more likely to be stopped by leg fatigue/discomfort than by dyspnoea, even when the same level of exercise is performed [17]. However, it has been suggested that in heart failure patients, when a ramp exercise protocol is used, the presence on the $V^{\prime} \mathrm{E} / V^{\prime} \mathrm{CO}_{2}$ relationship of an elevated $V^{\prime} \mathrm{E}$ intercept strongly suggest the coexistence lung disease $[18,19]$.

It is evident that the explanation for the pathophysiological processes underlying the perception of symptoms in heart failure patients is neither simple nor intuitive. The following sections will examine in greater details the potential contributions of various physiological systems to the generation of dyspnoea in patients with heart failure. In particular, the role of left and right ventricular function and haemodynamic performance, pulmonary function, gas-exchange anomalies, respiratory and peripheral muscular integrity and function, chemoreceptors and sympathetic nervous system will be reviewed.

\section{Is dyspnoea related to left and right ventricular haemodynamic performance?}

Numerous studies have demonstrated that, in patients with heart failure of various aetiologies, baseline left ventricular function is poorly correlated to peak exercise capacity [20-26]. In particular, left ventricular ejection fraction (LVEF) [20, 21, 23-26], E and A wave velocities [24] and right ventricular ejection fraction [21] have been shown to be poorly related to exercise capacity, although other markers of diastolic function may perform slightly better [22]. In addition, resting baseline left ventricular function is poorly associated with baseline dyspnoea and functional class $[20,24]$. Although these studies have not directly quantified the relationship between exertional dyspnoea and markers of ventricular function, it seems unlikely that these indices would provide a satisfactory estimation of the dyspnoea burden of heart failure patients given that exertional dyspnoea, even in this population, increases relatively linearly with exercise capacity [3].

Less data are available on the use of dynamic haemodynamic measurements during exercise. A study describing direct haemodynamic measurements in 64 patients with heart failure during incremental exercise testing showed no relationship between dynamic measurements of cardiac index or pulmonary artery wedge pressure and peak $V^{\prime} \mathrm{O}_{2}$. In addition, patients with mild, moderate or severe haemodynamic dysfunction during exercise reached similar values of peak $V^{\prime} \mathrm{O}_{2}$, suggesting that factors other than left ventricular function were limiting exercise in these patients [27]. Specific markers, such as a higher rest-stress change in mitral annulus systolic velocity (measured during dobutamine stress echocardiography) has been associated with better aerobic performance, despite no difference in resting LVEF between patients with a high or low rest-stress change during exertion [28].

Other studies reporting on pulmonary artery pressure monitoring during both maximal exercise and activities of daily living in patients with heart failure showed an inconsistent relationship between this variable and both dyspnoea and exercise capacity, again suggesting that central haemodynamic status alone is insufficient to explain exertional symptoms $[29,30]$.

Finally, therapeutic interventions for heart failure such as inotropic drugs [31, 32], nitrates [33] and phosphodiesterase-5 inhibitors [34], although they improve haemodynamic variables, do not provide a significant improvement on exercise capacity. In addition, heart failure treatment with angiotensin converting enzyme inhibitors and anti-aldosteronic drugs, noted to improve functional capacity, has been associated with lung diffusion improvement without pulmonary haemodynamic changes [35, 36]. Finally treatment with $\beta$-blocker agents has been shown to have little to no effect on maximal exercise capacity, but has been associated with an improvement in perceived dyspnoea and ventilatory response to exercise [37] particularly for non-selective $\beta$-blockers [38].

\section{Is dyspnoea related to pulmonary anomalies?}

Lung function and ventilation

The relevance of ventilatory response to exercise in heart failure lies in the fact that, as in other cardiopulmonary disorders, dyspnoea intensity rises during exercise as $V^{\prime} \mathrm{E}$ increases [3]. Anomalies in standard spirometry and alveolar capillary gas diffusion as well as in the ventilatory response to exercise in patients with heart failure are well documented and mostly relate to an exaggerated or disproportionally high ventilatory output compared to workload or carbon dioxide production $[6,39,40]$. The steepness with which $V^{\prime} \mathrm{E}$ rises with respect to $V^{\prime} \mathrm{CO}_{2}$ (i.e. the $V^{\prime} \mathrm{E} / V^{\prime} \mathrm{CO}_{2}$ slope) is usually increased in heart failure $[6,41-43]$, signifying that while a normal subject has to ventilate almost $20-25 \mathrm{~L} \cdot \mathrm{min}^{-1}$ per $1 \mathrm{~L} \cdot \mathrm{min}^{-1}$ of carbon dioxide produced, a patient with heart failure ventilates almost $30-50 \mathrm{~L} \cdot \mathrm{min}^{-1}$ for the same amount of carbon dioxide produced (figure 1). Although this observation has led to the development of valuable prognostic markers [41], its direct relationship to exertional dyspnoea remains unclear. 


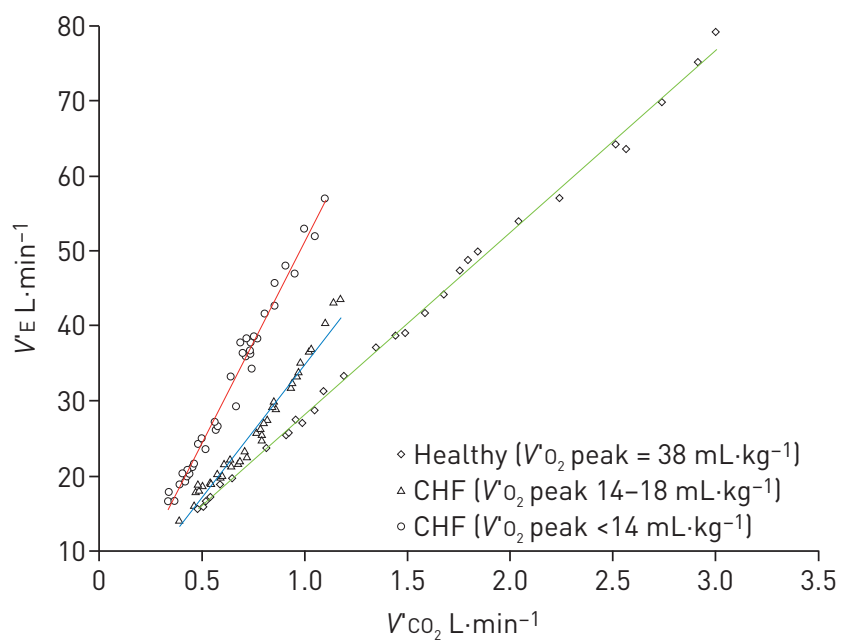

FIGURE 1 Examples of ventilatory efficiency slope (minute ventilation $\left(V^{\prime} E\right) /$ carbon dioxide production $\left(V^{\prime} \mathrm{CO}_{2}\right)$ slope) in a healthy subject (green line) and a patient with chronic heart failure (CHF) presenting with a peak oxygen uptake $\left(\mathrm{V}^{\prime} \mathrm{O}_{2}\right)$ between 14 and $18 \mathrm{~mL} \cdot \mathrm{kg}^{-1}$ (blue line) and a CHF patient presenting with a peak $V^{\prime} \mathrm{O}_{2}$ $<14 \mathrm{~mL} \cdot \mathrm{kg}^{-1}$ (red line).

The ventilatory response to exercise in heart failure is usually accompanied by an exaggerated breathing frequency and a diminished/truncated $V_{\mathrm{T}}$ response (figure 2) $[5,6,44]$. Although peak $V^{\prime} \mathrm{E}$ is generally diminished in patients with heart failure during exercise, submaximal $V^{\prime} \mathrm{E}$ is usually increased at any given work rate or $V^{\prime} \mathrm{O}_{2}[6,41-43]$ and dyspnoea intensity ratings are also increased at any given work rate, $V^{\prime} \mathrm{O}_{2}$ or $V^{\prime} \mathrm{E}$ [6] compared with age-matched healthy controls [3].

A study by KRAEMER et al. [45] suggested that baseline lung function parameters (in particular forced expiratory volume in $1 \mathrm{~s}$, forced vital capacity and diffusion capacity of the lung for carbon monoxide (DLCO)) related better to exercise capacity than resting haemodynamics. Although others have found that this relationship may be limited to heart failure patients with lower baseline dyspnoea levels [46], it is interesting to note that patients in the study by KRAEMER et al. [45] had mean spirometric variables that remained in the normal range. This finding raises the question of whether dynamic, rather that resting, pulmonary function may be implicated in the generation of the "excessive" ventilatory response to exercise in heart failure patients. Although dynamic respiratory mechanics has not extensively been studied in this population, a growing body of evidence suggests that dynamic lung hyperinflation, characterised by progressive increases in end-expiratory lung volume, as indirectly assessed by changes (decrease) in dynamic inspiratory capacity, may occur during exercise in heart failure patients and may impart significant "restrictive" constraints on VT expansion with development of critical mechanical limitation of $V^{\prime} \mathrm{E}[5,6,47]$, contributing to symptom limitation during exercise. Patients with heart failure show reduced resting static lung compliance, even in the absence of overt pulmonary oedema [48-51], associated with either restrictive or obstructive ventilatory defect on resting pulmonary function testing $[5,6,47,52,53]$. The nature of the airway dysfunction in heart failure is poorly understood and may reflect bronchial mucosal oedema, airway hyperresponsiveness, the attendant effects of ageing or tobacco smoking or various combinations of these factors [53-56]. The reduced resting expiratory reserve volume and the shape and limits of the maximal flow-volume curves in the tidal operating range along with the encroachment of $V \mathrm{~T}$ upon the maximal flow-volume envelope in heart failure patients strongly suggest that operating $V \mathrm{~T}$ is positioned closer to residual volume, thus increasing the propensity for expiratory flow limitation (figure 3) $[5,6,47,53]$. Heart failure patients who present with resting expiratory flow limitation have been shown to develop significant dynamic lung hyperinflation (as tracked by a decrease in dynamic inspiratory capacity) in the setting of increased ventilatory demand such as exercise (figures 3 and 4 ) $[5,6,47]$ suggesting that the mechanical time-constants for lung emptying may be delayed in heart failure patients to a degree that air trapping may be precipitated during the tachypnoea of exercise.

Although studies examining the ventilation to maximum voluntary ventilation ( $\left.V^{\prime} \mathrm{E} / \mathrm{MVV}\right)$ relationship generally do not suggest a ventilatory limitation in patients with heart failure $[3,5,6]$, this relationship may not be a valid index of the mechanical ventilatory constraints present during exercise, particularly in this population, as MVV is not a physiological measure of mechanical ventilatory capacity under natural conditions. In fact it is performed at high lung volumes where maximal expiratory flows are higher than usually used during exercise. Also, breathing frequency is higher and tidal volume is smaller during the MVV manoeuvre than during exercise and requires breathing efforts that cannot be sustained for more than a few seconds $[3,6]$. Therefore, MVV reflects a maximal volitional effort at a time when the respiratory muscles are 

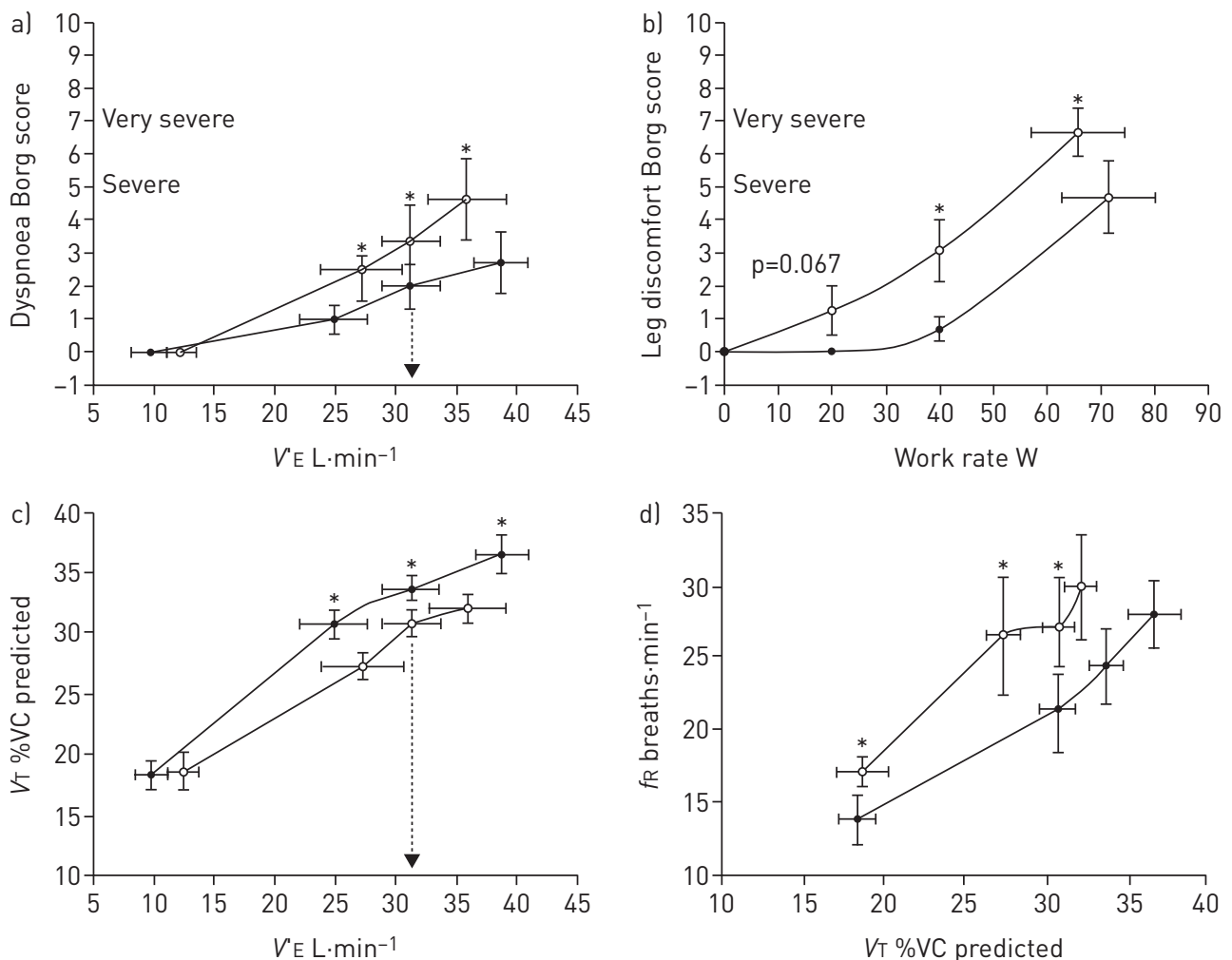

FIGURE 2 a) Exertional dyspnoea and b) leg discomfort intensity (Borg score) are shown in response to increasing minute ventilation $\left(V^{\prime} E\right)$ and/or work rate during symptom-limited incremental cycle exercise in patients with chronic heart failure during active biventricular pacing (filled circle) and inactive biventricular pacing lopen circle). Exertional dyspnoea and leg discomfort intensity (Borg score) were lower with active than with inactive biventricular pacing. Dyspnoea/ $V^{\prime} E$ and leg discomfort/work rate slopes were significantly $(p<0.05)$ steeper with inactive than with active biventricular pacing. Severe and very severe Borg scores are shown. c) Tidal volume ( $\mathrm{V} T$ ) expressed as \% of predicted vital capacity (\%VC predicated) in response to increasing $V^{\prime} E$ during symptom-limited incremental cycle exercise in patients with chronic heart failure during active biventricular pacing (filled circle) and inactive biventricular pacing (open circle). d) Respiratory frequency $\left(f_{R}\right)$ in response to expansion of $V_{T} \% \mathrm{VC}$ predicted. These two panels clearly show that the breathing pattern was deeper and slower with active compared with inactive biventricular pacing. Vertical dotted arrows represent iso- $V^{\prime} E$ point. Data are presented as mean $\pm S E$. *: $p<0.05$ active versus inactive biventricular pacing. Reproduced and adapted from [6] with permission from the publisher.

not competing for blood flow with locomotor muscles and are in a non-fatigued state. The breathing reserve is dependent on where one "chooses" to breathe relative to total lung capacity (TLC) and residual volume. At low lung volumes, the available maximal expiratory airflows are limited due to airway narrowing or closure and the resultant shape of the expiratory flow-volume curve. At high lung volumes, while considerable airflow is available, the elastic load on inspiration increases, which may be particularly detrimental to the patient with heart failure, whose inspiratory muscle may be weakened and/or ischaemic during exercise [57], and where increases in pressure no longer generate significant incremental volume change. Those factors could create a situation in which the pressure to breathe $\left(P_{\text {oes }}\right)$ represents a large fraction of maximal inspiratory pressure $\left(P_{\mathrm{i}, \mathrm{max}}\right)$, leading to an increased sense of breathing effort $\left(P_{\mathrm{oes}} / P_{\mathrm{i}, \mathrm{max}}\right)$. In keeping with this hypothesis, it is not surprising that dyspnoea at the end of exercise in patients with heart failure has been qualitatively described as unsatisfied inspiration and inspiratory difficulty [58]. D'ArsignY et al. [58] studied the contribution of mechanical factors to exertional dyspnoea and exercise intolerance in 12 patients with advanced heart failure by performing detailed flow-volume loop analysis during exercise and showed that both peak $V^{\prime} \mathrm{O}_{2}$ and the dyspnoea (Borg) $/ V^{\prime} \mathrm{O}_{2}$ slope correlated significantly with the resting $V \mathrm{~T} /$ inspiratory capacity ratio, i.e. constraints on $V \mathrm{~T}$ expansion. Fittingly, the majority of these patients selected qualitative descriptors of dyspnoea pertaining to "unsatisfied inspiratory effort" during exercise.

New insights into mechanisms of exertional dyspnoea in patients with advanced heart failure have emerged as a result of a study that used biventricular pacing to increase cardiac output during cardiopulmonary exercise testing [6]. LAVENEZIANA et al. [6] showed that biventricular pacing was associated with improved dyspnoea intensity at a given $V^{\prime} \mathrm{E}$ and $V^{\prime} \mathrm{O}_{2}$. The dyspnoea/ $V^{\prime} \mathrm{E}$ slopes were consistently reduced by $\sim 50 \%$ during exercise in response to active cardiac pacing. Improved dyspnoea and exercise performance during 

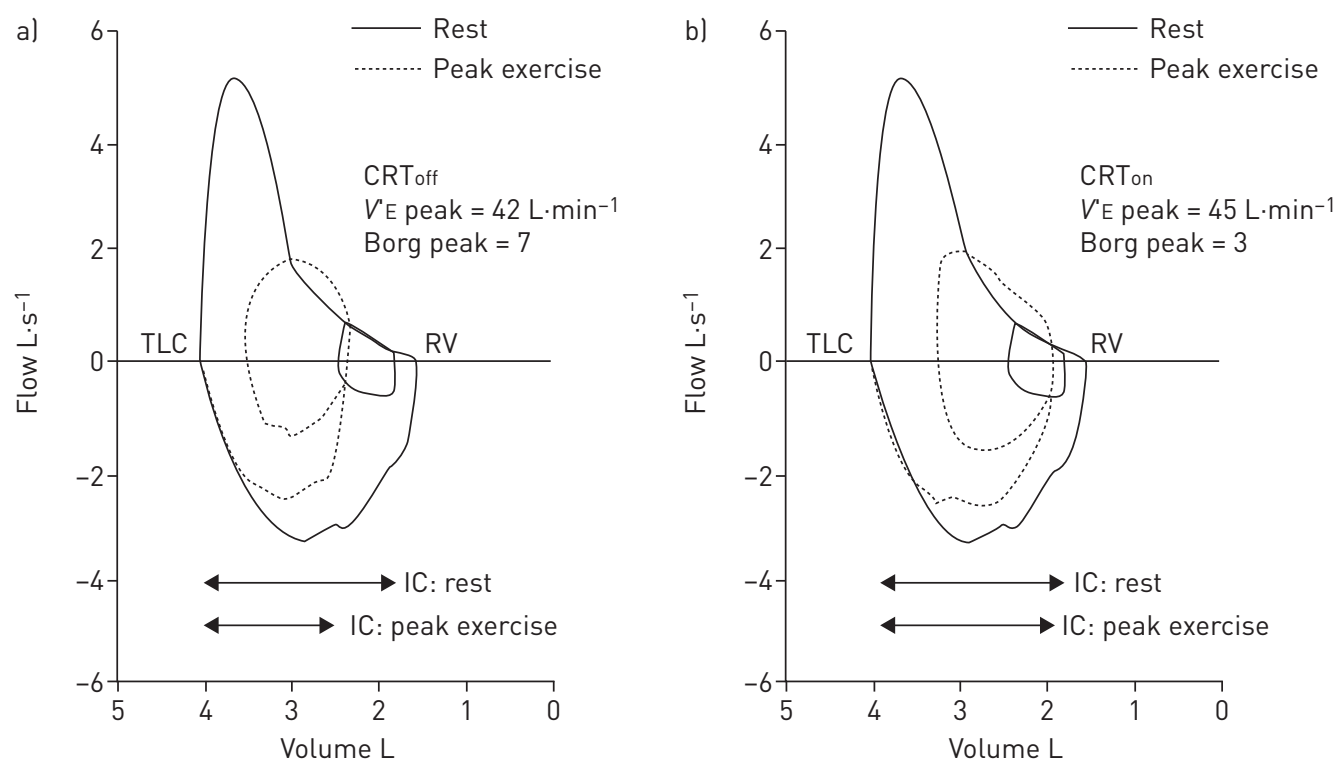

FIGURE 3 In a representative chronic heart failure patient, tidal flow-volume loops at rest (solid line) and at the peak of symptom-limited incremental exercise (dashed line) are shown relative to the maximal envelope following a) inactive biventricular pacing (CRToff), and b) active biventricular pacing (CRTon). Note expiratory flow-limitation (tidal expiratory flow overlapping the maximal curve) at rest and dynamic lung hyperinflation (as shown by reduction of inspiratory capacity (IC)) with persisting flow-limitation during exercise. $V^{\prime} E$ : minute ventilation; TLC: total lung capacity; RV: residual volume. Data from [6].

active pacing (compared with inactive pacing modality) were associated with a reduced ventilatory requirement likely due to: 1) delayed onset of metabolic acidosis secondary to improved oxygen delivery or utilisation or both (as suggested by a consistent increase in the anaerobic threshold), and 2) improved ventilation-perfusion $\left(V^{\prime} / Q^{\prime}\right)$ relationships as a result of an improved ability to reduce a higher physiological dead-space during exercise due to improved pulmonary perfusion (as suggested by the improved $V^{\prime} \mathrm{E} / V^{\prime} \mathrm{CO}_{2}$ slope and ratios). It is reasonable to assume that the attendant reduction in central respiratory drive is likely to ameliorate dyspnoea intensity in this occasion. Similarly, reducing excessive lung fluid by ultrafiltration improves right and left heart haemodynamics and increases exercise tidal volume and dynamic lung compliance $[7,59]$.

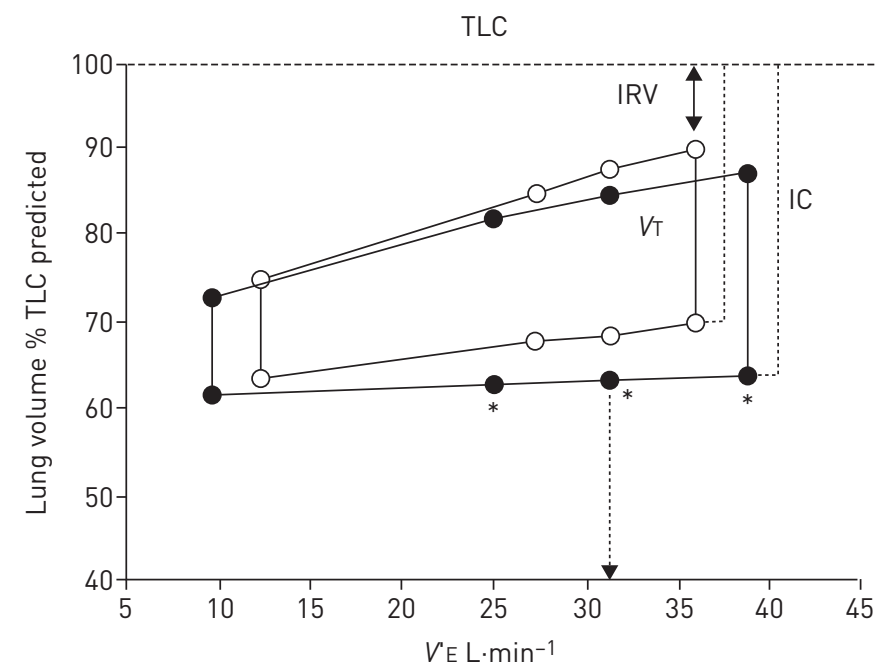

FIGURE 4 Changes in operating lung volumes expressed as \% of predicted total lung capacity (\%TLC predicted) are shown as minute ventilation $\left(V^{\prime} E\right)$ increases during symptom-limited incremental cycle exercise in patients with chronic heart failure following active biventricular pacing (filled circle) and inactive biventricular pacing lopen circle). "Restrictive" constraints on tidal volume (VT) expansion during exercise are significantly greater with inactive compared with active biventricular pacing from both below (reduced inspiratory capacity (IC)) and above (inspiratory reserve volume (IRV)). Vertical dotted arrow represents iso- $V^{\prime} E$ point. Data are presented as mean \pm SE. *: $p<0.05$ active versus inactive biventricular pacing. Reproduced and adapted from [6] with permission from the publisher. 


\section{Dynamic hyperinflation}

With the goal of examining the role of the ventilatory contribution to exertional dyspnoea of heart failure, O'Donnell et al. [5] examined the effects of inspiratory muscle unloading during symptom-limited constant-load exercise using a ventilator. Not surprisingly, during the unassisted control test, peak $V^{\prime} \mathrm{O}_{2}$ and ventilation were lower than normal in heart failure patients. These patients also had higher submaximal ventilation and experienced severe dyspnoea, and their ventilatory pattern was characterised by a relatively shallow $V \mathrm{~T}$ and a high respiratory rate. Furthermore, exercise flow-volume loop analysis demonstrated dynamic hyperinflation: there was a progressive rise in end-expiratory lung volume by an average of $0.26 \mathrm{~L}$. At a peak work rate of only $41 \%$ predicted, end-inspiratory lung volume (EILV) comprised $92 \%$ of TLC, suggesting that further expansion of $V \mathrm{~T}$ was not possible. Pressure support ventilation, which reduced the tidal inspiratory pleural pressure/time slope by an average of $44 \%$, did not affect submaximal dyspnoea ratings but, nevertheless, allowed patients to exercise for an additional 3 min (a $43 \%$ increase over the unassisted control test) at ventilation levels $>50 \mathrm{~L} \cdot \mathrm{min}^{-1}$ without experiencing any significant rise in dyspnoea. Pressure support also reduced perceived leg discomfort, which contributed importantly to the increased exercise endurance. Therefore, reduced contractile respiratory muscle effort is thought to be an important mechanism in dyspnoea relief in this setting. In this study, there were significant correlations between the decrease in exertional leg discomfort, the reduction in $V^{\prime} \mathrm{O}_{2} /$ time slopes and the reduction in Poes/time slopes, leading the authors to conclude that pressure support ventilation mainly allowed alleviation of leg discomfort by unloading the respiratory muscle (and, presumably, allowing a redistribution of blood flow to the exercising skeletal muscles), rather than by reducing of dynamic hyperinflation per se. This study and others [60] may therefore suggest that the reduction in inspiratory capacity during exercise in patients with heart failure may be predominantly mediated by respiratory muscle fatigue/dysfunction than by the effects of expiratory flow limitation. Although selected strategies aimed at unloading or training respiratory muscles have successfully improved exercise tolerance and sometimes symptoms perception in heart failure patients $[5,6,61-63]$, the exact prevalence of respiratory muscle weakness and its relationship to dyspnoea in heart failure is still not clear.

The question of whether the decrease in dynamic inspiratory capacity reflects the increase in end-expiratory lung volumes (dynamic lung hyperinflation) or the presence/development of respiratory muscle weakness/ fatigue during exercise in heart failure patients warrants attention. If we accept that total lung capacity (TLC) remains stable throughout exercise [47], we can assume that the decreases in dynamic inspiratory capacity reflect the increase in the rate of change in end-expiratory lung volumes. Alternatively, reduced cardiac function, by reducing oxygen delivery and inspiratory muscle regional blood flow, may have increased respiratory muscle fatigue and/or increase the competition for blood flow with locomotor muscles [64]. If this is the case, decreases in dynamic inspiratory capacity might reflect a decreased ability to reach TLC during the inspiratory capacity manoeuvres because of the presence/development of respiratory muscle weakness/fatigue; given this scenario, the alterations in breathing pattern response usually observed in heart failure patients at each stage of exercise may reflect decreased functional strength and/or weakness of the inspiratory muscles, although the role of the latter in heart failure remains conjectural.

Partial reversal of these mechanical abnormalities (i.e. decreased dynamic inspiratory capacity, $V \mathrm{~T}$ and inspiratory reserve volume) leads to alleviation of exertional dyspnoea in heart failure patients undergoing biventricular cardiac resynchronisation therapy, a result that supports the role of such mechanical factors in dyspnoea causation (figures 2-4) [6]. The observed improved dynamic inspiratory capacity (regardless of whether it was due to reduced dynamic lung hyperinflation or increased inspiratory muscle strength or both) resulting from active cardiac pacing would reduce the central motor command output (and central corollary discharge to the somatosensory cortex) required to drive the ventilatory muscles, thereby improving dyspnoea. In addition, the observed reduced breathing frequency in response to active cardiac pacing would also reduce the velocity of shortening of the inspiratory muscles and reduce dynamic functional weakness in this manner. Improved cardio-pulmonary interaction during active cardiac pacing in patients with heart failure may favourably alter activation patterns in mechanosensors in the lung, airways, heart and pulmonary vasculature and reduce unpleasant respiratory sensation in a manner that is not fully understood $[3,6]$. Therefore, improvements in dynamic respiratory mechanics and ventilatory muscle function along with changes in ventilatory control during exercise are all likely to have salutary sensory and mechanical consequences for patients with heart failure.

Dynamic lung hyperinflation in heart failure patients has been found to be associated with high $V \mathrm{~T} /$ inspiratory capacity ratios, marked reduction of the inspiratory reserve volume and more rapid, shallow breathing at each stage of exercise as well as at any given submaximal $V^{\prime} \mathrm{O}_{2}$ and $V^{\prime} \mathrm{E}$ (figures 2-4) $[5,6,47]$. A study by NANAS et al. [65] showed that resting inspiratory capacity predicted symptom-limited peak $V^{\prime} \mathrm{O}_{2}$ in heart failure patients better than any other resting pulmonary function or haemodynamic parameter, confirming the importance of restrictive ventilatory mechanics. 
We cannot therefore neglect that dynamic lung hyperinflation during exercise in heart failure patients would be expected to be associated with "high-end" mechanics, as in other restrictive lung diseases. Increased elastic loading of inspiratory muscles, weakened by an increased velocity of shortening, could also contribute significantly to ventilatory constraints in heart failure patients $[5,6]$. It is conceivable, therefore, that interventions that improve, directly or indirectly, dynamic ventilatory mechanics during exercise would improve exertional symptoms and physical performance in these patients [5, 6]. Further studies that engage oesophageal pressure measurements to evaluate directly abnormalities in respiratory mechanics and that contain a large number of heart failure patients are needed to definitively elucidate the mechanistic link between respiratory mechanics and exercise symptoms perception and limitation in this population [59].

\section{$\mathbf{V}^{\prime} / \mathbf{Q}^{\prime}$ mismatching}

When considering other respiratory sources of exertional dyspnoea in heart failure patients, the potential role of $V^{\prime} / Q^{\prime}$ mismatches must be evoked. Indeed, as the main ventilatory characteristic of patients with heart failure during exercise is an increased ventilatory response to carbon dioxide production levels (abnormally high ventilatory equivalent for carbon dioxide) [66], one could suspect the presence of pathologic increases in dead space (which is closely related to the $V^{\prime} \mathrm{E} / V^{\prime} \mathrm{CO}_{2}$ relationship, as evident from the alveolar ventilation equation). Conceptually, increases in dead space in patients with heart failure could be secondary to the rapid and shallow breathing pattern of heart failure patients on exertion or to the inability of a failing right ventricle to homogeneously perfuse the lungs [67]. Although some studies have indeed found relationships between the increased $V^{\prime} \mathrm{E} / V^{\prime} \mathrm{CO}_{2}$ slope and fractional dead space ventilation in heart failure patients $[66,68]$, they have been criticised for deriving their measurement of fractional dead space ventilation using the alveolar (rather than gas) ventilation equation, in which $V^{\prime} \mathrm{E} / V^{\prime} \mathrm{CO}_{2}$ and dead space are intrinsically linked [69]. Other studies evaluating the prevalence and impact of $V^{\prime} / Q^{\prime}$ matching changes during exercise in patients with heart failure showed that arterial hypoxaemia was rare [70] and that, when compared to control subjects, a decrease in fractional dead space ventilation could be observed in both groups, as well as a similar fall in arterial carbon dioxide tension, increase in alveolar-arterial oxygen gradient and arterial oxygen tension [43]. It seems unlikely therefore that the $V^{\prime} / Q^{\prime}$ mismatches that may occur during exercise in heart failure patients are the leading mechanistic cause for increased relative ventilation during exercise in these patients.

\section{Alveolar-capillary membrane dysfunction}

The lungs can withstand significant alveolar-capillary membrane impairment without low arterial oxygen saturation $\left(\mathrm{SaO}_{2}\right)$. Indeed, in heart failure patients, a low $\mathrm{SaO}_{2}$ at rest or after alveolar-capillary membrane challenge such as fluid overload or exercise is an unusual event [71-73]. In healthy subjects, rapid infusion of saline is associated to a slight reduction of spirometric parameters but an unchanged DLCO and $\mathrm{SaO}_{2}[74,75]$. Moreover, acute saline infusions reduce peak $V^{\prime} \mathrm{O}_{2}$ and increase ventilation inefficiency during exercise, as demonstrated by an increase in the slope of $V^{\prime} \mathrm{E} / V^{\prime} \mathrm{CO}_{2}[74,75]$. However, when normal subjects are pretreated with $\beta$-blockers during fluid overload, DLCO declines due to a reduction of the membrane conductance component of DLCO, with a partially compensatory capillary volume increase. The DLCO reduction is greater when a $\beta 1-\beta 2$ blocker (carvedilol) is used compared with a $\beta 1$ selective blocker (bisoprolol) (figure 5) [74]. In contrast, heart failure patients show a decrease in DLCO with even a small amount of saline infusion or physical exercise [71-73], suggesting that the lung fluid balance is in a critical condition. Indeed, in heart failure the alveolar-capillary membrane undergoes an extensive remodelling process. This remodelling includes fibrosis of the lung parenchyma, increased connective tissue deposition and small blood clots in the
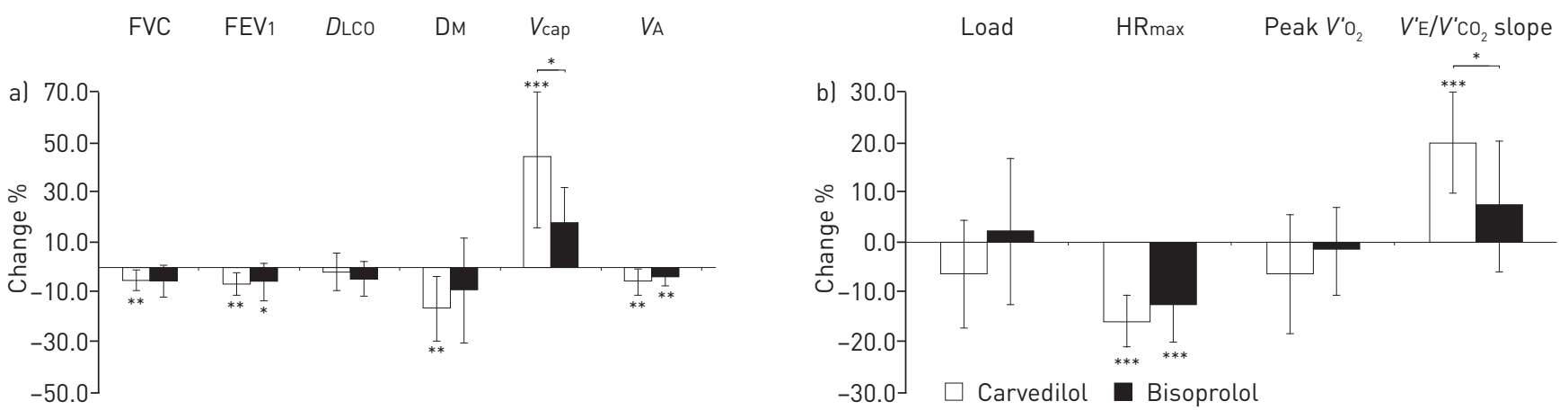

FIGURE 5 Change in physiological variables from baseline values a) at rest and b) during exercise after saline infusion and exposition to different $\beta$-blocker agents in healthy subjects. FVC: forced vital capacity; FEV1: forced expiratory volume in $1 \mathrm{~s}$; DLco: diffusing capacity of the lung for carbon monoxide; $D$ M: membrane diffusion; $V_{\text {cap }}$ : capillary volume; $V_{A}$ : alveolar volume; HRmax: maximum heart rate; $V^{\prime} O_{2}$ : oxygen uptake; $V^{\prime} E$ : minute ventilation; $V^{\prime} \mathrm{CO}_{2}$ : carbon dioxide production. ${ }^{*}$ : $\mathrm{p}<0.05 ;{ }^{* *}$ : $\mathrm{p}<0.01 ;{ }^{* * *}$ : $\mathrm{p}<0.001$. Reproduced and adapted from [74] with permission from the publisher. 
lung $[71,76,77]$. This process negatively influences the main physiological duties of the alveolar-capillary membrane, which are gas exchange and lung fluid homeostasis. It has been shown that the impairment in DLCO mirrors the severity of heart failure [40], that DLCO has an independent prognostic role in heart failure [78], and that the alveolar-capillary membrane is recognised as a target of heart failure treatment [38]. Indeed, several categories of heart failure drugs, such as angiotensin converting enzyme inhibitors [35] and anti-aldosteronic drugs [36] improve gas diffusion across the alveolar-capillary membrane, while others have no influence, such as AT1-blockers [79], or even a negative action, such as $\beta 1-\beta 2$ blockers [38]. Interestingly, when lung over-hydration of subjects with heart failure is reduced by ultrafiltration, lung mechanics improves but DLCO remains unchanged [76]. Despite these findings, evidence supporting a direct correlation between dyspnoea and DLCO in patients with heart failure is lacking, as is evidence supporting a correlation between DLCO changes during fluid overload or exercise and dyspnoea changes.

Are the ventilatory anomalies of patients with heart failure related to chemo- and ergoreflexes? Animal studies have suggested that alterations in the chemoreflex might be present in the setting of heart failure, and have led to the hypothesis that increased chemoreceptor sensitivity could have a causative role in the excessive ventilation observed in heart failure patients [80]. Rabbit models have shown that peripheral, rather than central chemoreceptor sensitivity is increased in heart failure and is related to sympathetic activation and $V^{\prime} E[81,82]$. In humans, CHUA and colleagues [83, 84] showed that hypoxic and central hypercapnic chemosensivity were increased in subjects with heart failure compared with controls, and were related to the ventilatory response to exercise. In the clinical context however, it seems difficult to reconcile these findings and the augmented ventilatory response of heart failure patients during exercise, knowing that these patients most often maintain normal or near-normal levels of arterial oxygen tension and end-tidal carbon dioxide tension during exercise [42, 44, 85-88]. As such, other sources of ventilatory stimulation have been suggested, such as an increased ergoreceptor drive in peripheral skeletal muscle [89, 90]. Indeed, as for the respiratory muscles, the peripheral skeletal muscles of patients with heart failure show various morphological, histological, enzymatic and metabolic anomalies that translate into a clinically significant myopathy. Patients with heart failure frequently present with a cachectic syndrome in which muscle mass loss (sarcopenia) and dysfunction is a prominent feature, with important negative prognostic implications [91-93]. Histologically, studies on patients with heart failure have consistently described muscle fibre atrophy, decreased strength and endurance and abnormalities in capillary vascularisation [94-96] along with a shift from type I (slow-twitch) to type II (fast-twitch) muscle fibres [57, 96-98]. Molecular changes include higher lactate levels, higher lactate dehydrogenase activity and lower oxidative enzyme activity in heart failure patients compared with control subjects [96, 97], as well as lower phosphocreatine concentrations [99] and more rapid development of acidosis on exertion [96, 99, 100].

Among the mechanisms thought to mediate the changes in body composition and muscular abnormalities in heart failure patients are the overactivity of the sympathetic nervous system as well as alterations in the regulation of various cytokine systems and neurohumoral components, including tumour-necrosis alpha, catecholamines, cortisol, renin-aldosterone, neuropeptide Y, leptin ghrelin, adiponectin, growth hormone, insulin and insulin growth factor-1 [101-103]. Although decreased oxygen delivery and perfusion of the exercising muscles in patients with failing cardiac function seems an attractive mechanism by which the peripheral muscle abnormalities may develop, data on this question are equivocal. VolTERRANi et al. [104] studied 20 patients with heart failure and found a correlation between peak $V^{\prime} \mathrm{O}_{2}$ and quadriceps muscle strength, but not with indices of peripheral blood flow. Similarly, others have reported that among patients with heart failure, there was a subset of subjects with normal leg blood flow during exercise that nonetheless stopped exercising because of leg fatigue and had abnormally high elevations in femoral venous lactate levels, suggesting that exercise limitation was more dependent on intrinsic peripheral muscle dysfunction than on reduced blood flow [105]. Whether disuse atrophy could be an additional factor explaining the changes observed in the muscular function and metabolism of heart failure patients is also unclear but data suggests that deconditioning alone cannot account for the peripheral muscle dysfunction of these patients, especially in men $[106,107]$.

Overall, these data make a good point of relating the peripheral muscle dysfunction of heart failure patients and exercise limitation due to leg fatigue, but its potential relationship to exertional dyspnoea is less intuitive. However, a considerable body of data suggest that the peripheral skeletal muscles may be a key player in the generation of dyspnoea in heart failure patients, thought the action of mecano- and metaboreceptors (termed ergoreceptors) found in skeletal muscles. Mecanoreceptors (myelinated type III afferents) respond to the mechanical stimulus of the exercising muscle and that metaboreceptors (unmyelinated type IV afferents) are stimulated by acidosis, prostaglandins and bradykinins [108]. Together, these ergoreceptors mediate a reflex response to exercise (the ergoreflex) that induces an activation of the sympathetic tonus, tachycardia, vasoconstriction of muscles that are not being exercised and, importantly, an increase in pulmonary ventilation. Under normal circumstances, the ergoreflex 
therefore serves as a physiological stimulus contributing to the adaptation of the cardiopulmonary system to exercise. In patients with heart failure however, the early metabolic acidosis and local muscular metabolic abnormalities contribute to an exaggerated activation of the ergoreflex with, among other consequences, a disproportional increase in the ventilatory response to exercise (i.e. an elevated $V^{\prime} \mathrm{E} / V^{\prime} \mathrm{CO}_{2}$ slope). In a thought-provoking experiment, PiePoli et al. [90] reported on the contribution of the ergoreflex to the exaggerated ventilatory response to exercise in patients with heart failure. Following a bout of upper limb exertion until exhaustion, regional circulatory occlusion was performed by inflating a cuff proximal to the exercising muscle for $3 \mathrm{~min}$, effectively trapping the metabolites produced by exercise. Exercise induced a larger increase in ventilation in heart failure patients compared to controls and, importantly, the ventilatory rate remained at the same level as maximum exertion during the whole period of cuff inflation in heart failure patients, whereas it decreased rapidly to almost baseline levels in healthy subjects. Ergoreflex hyperactivation in the upper and lower limb has also been shown to be correlated to exercise performance and ventilatory efficiency $\left(V^{\prime} \mathrm{E} / V^{\prime} \mathrm{CO}_{2}\right.$ slope) in heart failure, and predominant in subjects with cachexia and muscle mass depletion [89, 109, 110]. Isolated study of the mecanoreceptors by applying passive movements to the peripheral limbs has been attempted and showed no significant difference in the increase in ventilation induced by passive movements between heart failure patients and control subjects, suggesting that the ergoreflex may mainly be mediated by metabo- rather than mecanoreceptors [111].

In light of these findings, therapeutic interventions aiming at improving the neurohumoral processes implicated in the ergoreflex response to exercise in heart failure patients may be expected to improve exercise tolerance and the ventilatory response to exercise in these subjects. Exercise training has been shown to improve the sympathovagal and ventilatory responses to exercise in patients with heart failure [112], a finding that may be mediated by a reduction of the exaggerated ergoreflex [90].

Taken together, these results support an important contribution of the peripheral musculature to the abnormal response to exercise in patients with heart failure, especially with regards to the ventilatory response.

\section{Is dyspnoea related to respiratory muscle dysfunction or fatigue?}

$P_{i, \max }$ and transdiaphragmatic twitch pressure elicited by phrenic nerve stimulation are about $20-30 \%$ below normal in patients with chronic heart failure [113-121]. Some of these data also suggest that the degree of impairment in respiratory muscle function parallels the severity of the cardiac dysfunction, its aetiology [115, 118-121], clinical prognosis [122] and, interestingly, increased peripheral chemosensitivity [123], a finding possibly related to an increase in sympathetic activation [124]. Importantly, some investigators have also reported on the relationship between the severity of respiratory muscle dysfunction and baseline dyspnoea [117], exertional dyspnoea [125], peak $V^{\prime} \mathrm{O}_{2}$ [119] and the abnormal $V^{\prime} \mathrm{E} / V^{\prime} \mathrm{CO}_{2}$ slope [121] in patients with heart failure. In particular, KASAHARA et al. [121] studied respiratory muscle function in 66 patients with stable heart failure that underwent cardiopulmonary exercise testing. They found that $P \mathrm{i}$,max decreased with worsening baseline functional status (New York Heart Association classification), and was one of the only independent predictors (along with age) of some of the ventilatory anomalies most commonly encountered in heart failure during exercise (rapid shallow breathing and $V^{\prime} \mathrm{E} / V^{\prime} \mathrm{CO}_{2}$ slope). In this study, there were also modest, but significant correlations between dyspnoea at peak exercise and $\mathrm{Pi}$,max, $V^{\prime} \mathrm{E} / V^{\prime} \mathrm{CO}_{2}$ slope and the $V \mathrm{~T} /$ respiratory rate ratio. These results therefore suggest the potential role of the respiratory muscles as mediators of the anomalies in respiratory pattern observed in heart failure during exercise, and the possible yet conjectural implication of their dysfunction in the subjective experience of exertional dyspnoea in heart failure patients.

Despite several findings suggestive of incipient fatigue, such as a such as the tension-time index of the diaphragm (TTIdi) at peak exercise of 0.10 in patients with advanced heart failure versus 0.03 in healthy subjects [125] a decrease in maximal inspiratory [60, 125] and expiratory pressures [125] at the end of maximal exercise, diaphragm fatigue after maximal incremental cycle exercise testing has never been clearly showed using phrenic nerve stimulation in a heart failure population.

\section{Muscle perfusion}

Interestingly, there is evidence that rats may protect diaphragm blood flow during exercise despite severe left ventricle dysfunction [126]. Johnson et al. [127] showed that both heart failure and healthy subjects achieved inspiratory tidal flows that approached a similar percent of the maximal available inspiratory flows, suggesting that the inspiratory flow-generating reserve of the inspiratory muscles at peak exercise was similar (but occurred at lower lung volumes in the heart failure patients) in heart failure patients and controls. It has also been postulated that reduced cardiac output that occurs during exercise in patients with heart failure may result in respiratory muscle ischaemia and ultimately in respiratory muscle fatigue [125, 128]. To investigate whether muscle underperfusion results in low frequency respiratory muscle fatigue, MANCINI et al. [125] performed supramaximal bilateral transcutaneous phrenic nerve stimulation before and 
immediately after maximal cycle exercise in heart failure and normal subjects. In both normal and heart failure subjects all parameters of diaphragmatic function (maximal rate of contraction and relaxation, peak twitch tension and maximal transdiaphragmatic pressure $(P \mathrm{di}))$ were unchanged before and after cycle exercise. Moreover, mean resting and peak $P$ di as well as peak TTIdi were greater in heart failure, but far from the occurrence of fatigue (the fatigue threshold being 0.15 ). Significant negative correlations were also found between ratings of perceived dyspnoea and maximal inspiratory and expiratory pressures, while a positive correlation linked the TTIdi with the Borg score of dyspnoea. However, taking into account the value of TTIdi, this correlation is unlikely to be clinically meaningful.

In another study, Hughes et al. [113] using oesophageal and gastric catheters as a volitional technique (sniff $P \mathrm{di}$ ) and magnetic phrenic nerve stimulation as a non-volitional technique (twitch $P \mathrm{di}$ ), were able to find a significant decrease in diaphragm strength as assessed by sniff $P$ di in heart failure patients compared with controls. However, paired phrenic nerve stimulation assessed to investigate a possible adaptation of force frequency characteristics of the diaphragm, showed a trend to increase twitch summation at $5-20 \mathrm{~Hz}$ in heart failure patients. This pattern, which is the opposite of the changes observed in low frequency fatigue, suggested to the authors an alteration in contractility of the diaphragm possibly explained by increased proportion of slow-twitch fibres. However, a relatively mild diaphragm weakness was not deemed to be clinically important in the study conditions. These results cast doubt on the findings of reduction of volitional measures of inspiratory muscle pressure (see $P$ i,max) after exercise being associated with prolonged early recovery of oxygen kinetics, as a partial explanation of the role played by respiratory muscles in exercise intolerance and symptoms limitation in heart failure patients $[60,129]$.

\section{Respiratory muscle endurance}

In addition to respiratory muscle weakness, muscle endurance in patients with heart failure is decreased to levels reaching about half that in healthy subjects [130], and this decrease seems disproportionate to the reduction in inspiratory and expiratory strength [130]. Several mechanisms may be involved. First, the circulatory supply of energy substrates during diaphragmatic loading increases less in animals with heart failure than in healthy animals [131]. Secondly, hyperpnoea during endurance testing could predispose to hyperinflation [5] as a consequence of expiratory flow-limitation [53]. Thirdly, the workload of the diaphragm is increased [125] because of decreased static lung compliance in patients with heart failure and pulmonary congestion [132] or pleural effusions.

\section{Mechanisms of structural and functional respiratory muscle changes in heart failure}

Several mechanisms can be evoked to explain the prevalent inspiratory muscle weakness in patients with heart failure. First, animal models have shown that the total number of diaphragmatic actin-myosin cross-bridges is decreased in heart failure, a finding that could be modulated by exposure to angiotensin converting enzyme inhibition [133]. Secondly, type IIb ("fast") muscles fibres, which have been reported to produce 1.5 to 2.0 times more force than type I ("slow") fibres [134], are fewer in patients with heart failure [135]. Thirdly, the cross-sectional area of all types of fibres of the diaphragm and rrelateib cage muscles is reduced in humans with heart failure [136] and in a pig model of heart failure [137]. Potential mechanisms participating in the development of these histological changes include decreased regional blood flow [131] and activation of the ubiquitin-proteasome proteolytic pathway by tumour necrosis factor [138]. Fourthly, voluntary drive to the respiratory muscles during maximal inspiratory efforts may be decreased in patients with heart failure [125] and finally, significant oxygen desaturation can be observed in the accessory respiratory muscles of heart failure patients during exercise [125, 139], a finding thought to be related to insufficient oxygen delivery to the respiratory muscles and to a greater work of breathing in the setting of increased metabolic demand in these patients [128, 140].

The resting length of muscles (as indirectly quantified by the normal or decreased value of functional residual capacity) is usually preserved and thus probably cannot explain the inspiratory muscle weakness.

\section{Therapeutic interventions targeting the respiratory muscles}

Studies focusing on therapeutic interventions aiming at improving respiratory muscle function in patients with heart failure have showed that muscle strength can be increased by selective respiratory muscle training [141, 142], nasal continuous positive airway pressure [114] or angiotensin converting enzyme inhibitors [133], and that respiratory muscle training was associated with improvement in the ventilatory response to exercise $[61,143]$. MANCINI et al. [141], showed that selective training of the respiratory muscles reduces dyspnoea, improves respiratory muscle strength and endurance, and increases exercise capacity. The benefits of training may result from improved intrinsic properties of the respiratory muscles, a learning effect, and desensitisation to dyspnoea. In the only randomised controlled trial, however, JoHnson et al. [142] found that domiciliary inspiratory muscle training improved inspiratory strength but not exercise capacity. The results of MANCINI et al. [141] may have been positive because of the more intense supervision 
(hospital-based programme) and training protocol (including expiratory muscle training), and more severe baseline inspiratory muscle weakness than was the case for the patients of JoHNson et al. [142] Overall, however, these studies are often marred by small numbers of patients, varying aetiology and severity of heart failure, and occasional lack of control groups [141]. The improvement in muscle capacity following these interventions may result from increased size of muscle fibres, increased number of cross-bridges, improved perfusion, and enhanced recruitment during voluntary efforts [114, 133].

\section{Conclusion}

Exertional dyspnoea is among the dominant symptoms in patients with chronic heart failure and progresses relentlessly as the disease advances, leading to reduced ability to function and engage in activities of daily living. Effective management of this disabling symptom awaits a better understanding of its underlying physiology.

Cardiovascular factors are believed to play a major role in dyspnoea causation in heart failure patients. However, despite pharmacological interventions such as vasodilators or inotropes that improve central haemodynamics, patients with heart failure still complain of exertional dyspnoea. Clearly, dyspnoea is not determined by cardiac factors alone, but likely depends on complex, integrated cardio-pulmonary, neurohormonal and peripheral interactions.

From our knowledge of the source and mechanisms of dyspnoea in cardiorespiratory diseases, we can postulate that the mechanisms of exertional dyspnoea in patients with heart failure are multifaceted and potentially include: 1) increased vascular congestion/distension and interstitial oedema; 2) increased ventilatory demand (secondary to increased $V^{\prime} / Q^{\prime}$ mismatching and to chemo-, metabo- and ergo-reflexes); 3 ) dynamic lung hyperinflation and excessive loading (due to decreased lung compliance from pulmonary oedema or increased airways resistance) of inspiratory muscles; and 4) ventilatory and peripheral muscle dysfunction.

It emerges that any intervention targeted to reducing the excessive ventilatory demand during activity, improving dynamic respiratory mechanics and respiratory/peripheral muscle function should alleviate the perception of exertional symptoms and consequently improve exercise performance in the heart failure population.

\section{References}

1 Mozaffarian D, Benjamin EJ, Go AS, et al. Heart disease and stroke statistics 2016 update: a report from the American Heart Association. Circulation 2016; 133: e38-e360.

2 Ponikowski P, Anker SD, AlHabib KF, et al. Heart failure: preventing disease and death worldwide. ESC Heart Fail 2014; 1: 4-25.

3 Laviolette L, Laveneziana P. Dyspnoea: a multidimensional and multidisciplinary approach. Eur Respir J 2014; 43: $1750-1762$.

4 Laveneziana P, Similowski T, Morelot-Panzini C. Multidimensional approach to dyspnea. Curr Opin Pulm Med 2015; 21: 127-132.

5 O'Donnell D, D'Arsigny C, Raj S, et al. Ventilatory assistance improves exercise endurance in stable congestive heart failure. Am J Respir Crit Care Med 1999; 160: 1804-1811.

6 Laveneziana P, O’Donnell D, Ofir D, et al. Effect of biventricular pacing on ventilatory and perceptual responses to exercise in patients with stable chronic heart failure. J Appl Physiol 2009; 106: 1574-1583.

7 Agostoni PG, Marenzi GC, Pepi M, et al. Isolated ultrafiltration in moderate congestive heart failure. J Am Coll Cardiol 1993; 21: 424-431.

8 Clark AL, Sparrow JL, Coats AJ. Muscle fatigue and dyspnoea in chronic heart failure: two sides of the same coin? Eur Heart J 1995; 16: 49-52.

9 Hamilton AL, Killian KJ, Summers E, et al. Muscle strength, symptom intensity, and exercise capacity in patients with cardiorespiratory disorders. Am J Respir Crit Care Med 1995; 152: 2021-2031.

10 Hamilton AL, Killian KJ, Summers E, et al. Symptom intensity and subjective limitation to exercise in patients with cardiorespiratory disorders. Chest 1996; 110: 1255-1263.

11 Russell SD, McNeer FR, Higginbotham MB. Exertional dyspnea in heart failure: a symptom unrelated to pulmonary function at rest or during exercise. Duke University Clinical Cardiology Studies (DUCCS) Exercise Group. Am Heart J 1998; 135: 398-405.

12 Gandevia SC. Neural mechanisms underlying the sensation of breathlessness: kinesthetic parallels between respiratory and limb muscles. Aust N Z J Med 1988; 18: 83-91.

13 Gandevia SC, McCloskey DI. Changes in motor commands, as shown by changes in perceived heaviness, during partial curarization and peripheral anaesthesia in man. J Physiol 1977; 272: 673-689.

14 McCloskey DI, Ebeling P, Goodwin GM. Estimation of weights and tensions and apparent involvement of a "sense of effort". Exp Neurol 1974; 42: 220-232.

15 Sinoway LI, Smith MB, Enders B, et al. Role of diprotonated phosphate in evoking muscle reflex responses in cats and humans. Am J Physiol 1994; 267: H770-H778.

16 Lipkin DP, Canepa-Anson R, Stephens MR, et al. Factors determining symptoms in heart failure: comparison of fast and slow exercise tests. Br Heart J 1986; 55: 439-445.

17 Witte KK, Clark AL. Cycle exercise causes a lower ventilatory response to exercise in chronic heart failure. Heart 2005; 91: 225-226.

18 Apostolo A, Laveneziana P, Palange P, et al. Impact of chronic obstructive pulmonary disease on exercise ventilatory efficiency in heart failure. Int J Cardiol 2015; 189: 134-140. 

measurements. PLoS One 2014; 9: e87395.

20 Carell ES, Murali S, Schulman DS, et al. Maximal exercise tolerance in chronic congestive heart failure. Relationship to resting left ventricular function. Chest 1994; 106: 1746-1752.

21 Clark AL, Swan JW, Laney R, et al. The role of right and left ventricular function in the ventilatory response to exercise in chronic heart failure. Circulation 1994; 89: 2062-2069.

22 Davies SW, Fussell AL, Jordan SL, et al. Abnormal diastolic filling patterns in chronic heart failure: relationship to exercise capacity. Eur Heart J 1992; 13: 749-757.

23 Higginbotham MB, Morris KG, Conn EH, et al. Determinants of variable exercise performance among patients with severe left ventricular dysfunction. Am J Cardiol 1983; 51: 52-60.

24 Witte KK, Nikitin NP, De Silva R, et al. Exercise capacity and cardiac function assessed by tissue Doppler imaging in chronic heart failure. Heart 2004; 90: 1144-1150.

25 Benge W, Litchfield RL, Marcus ML. Exercise capacity in patients with severe left ventricular dysfunction. Circulation 1980; 61: 955-959.

26 Franciosa JA, Park M, Levine TB. Lack of correlation between exercise capacity and indexes of resting left ventricular performance in heart failure. Am J Cardiol 1981; 47: 33-39.

27 Wilson JR, Rayos G, Yeoh TK, et al. Dissociation between peak exercise oxygen consumption and hemodynamic dysfunction in potential heart transplant candidates. J Am Coll Cardiol 1995; 26: 429-435.

28 Ciampi Q, Pratali L, Porta MD, et al. Tissue Doppler systolic velocity change during dobutamine stress echocardiography predicts contractile reserve and exercise tolerance in patients with heart failure. Eur Heart $J$ Cardiovasc Imaging 2013; 14: 102-109.

29 Gibbs JS, Keegan J, Wright C, et al. Pulmonary artery pressure changes during exercise and daily activities in chronic heart failure. J Am Coll Cardiol 1990; 15: 52-61.

30 Szlachcic J, Massie BM, Kramer BL, et al. Correlates and prognostic implication of exercise capacity in chronic congestive heart failure. Am J Cardiol 1985; 55: 1037-1042.

31 Ribeiro JP, White HD, Arnold JM, et al. Exercise responses before and after long-term treatment with oral milrinone in patients with severe heart failure. Am J Med 1986; 81: 759-764.

32 Wilson JR, Martin JL, Ferraro N. Impaired skeletal muscle nutritive flow during exercise in patients with congestive heart failure: role of cardiac pump dysfunction as determined by the effect of dobutamine. Am J Cardiol 1984; 53: 1308-1315.

33 Franciosa JA, Cohn JN. Effect of isosorbide dinitrate on response to submaximal and maximal exercise in patients with congestive heart failure. Am J Cardiol 1979; 43: 1009-1014.

34 Redfield MM, Chen HH, Borlaug BA, et al. Effect of phosphodiesterase-5 inhibition on exercise capacity and clinical status in heart failure with preserved ejection fraction: a randomized clinical trial. JAMA 2013; 309: $1268-1277$.

35 Guazzi M, Marenzi G, Alimento M, et al. Improvement of alveolar-capillary membrane diffusing capacity with enalapril in chronic heart failure and counteracting effect of aspirin. Circulation 1997; 95: 1930-1936.

36 Agostoni P, Magini A, Andreini D, et al. Spironolactone improves lung diffusion in chronic heart failure. Eur Heart J 2005; 26: 159-164.

37 Laveneziana P, Agostoni P, Mignatti A, et al. Effect of acute $\beta$-blocker withholding on ventilatory efficiency in patients with advanced chronic heart failure. J Card Fail 2010; 16: 548-555.

38 Contini M, Apostolo A, Cattadori G, et al. Multiparametric comparison of CARvedilol, versus NEbivolol, versus BIsoprolol in moderate heart failure: the CARNEBI trial. Int J Cardiol 2013; 168: 2134-2140.

39 Agostoni P, Cattadori G, Guazzi M, et al. Cardiomegaly as a possible cause of lung dysfunction in patients with heart failure. Am Heart J 2000; 140: e24.

40 Agostoni P, Bussotti M, Cattadori G, et al. Gas diffusion and alveolar-capillary unit in chronic heart failure. Eur Heart J 2006; 27: 2538-2543.

41 Kleber FX, Vietzke G, Wernecke KD, et al. Impairment of ventilatory efficiency in heart failure: prognostic impact. Circulation 2000; 101: 2803-2809.

42 Clark AL, Volterrani M, Swan JW, et al. The increased ventilatory response to exercise in chronic heart failure: relation to pulmonary pathology. Heart 1997; 77: 138-146.

43 Clark AL, Volterrani M, Swan JW, et al. Ventilation-perfusion matching in chronic heart failure. Int J Cardiol 1995; 48: 259-270.

44 Wasserman K, Zhang YY, Gitt A, et al. Lung function and exercise gas exchange in chronic heart failure. Circulation 1997; 96: 2221-2227.

45 Kraemer MD, Kubo SH, Rector TS, et al. Pulmonary and peripheral vascular factors are important determinants of peak exercise oxygen uptake in patients with heart failure. J Am Coll Cardiol 1993; 21: 641-648.

46 Ingle L, Shelton RJ, Cleland JG, et al. Poor relationship between exercise capacity and spirometric measurements in patients with more symptomatic heart failure. J Card Fail 2005; 11: 619-623.

47 Agostoni P, Pellegrino R, Conca C, et al. Exercise hyperpnea in chronic heart failure: relationships to lung stiffness and expiratory flow limitation. J Appl Physiol 2002; 92: 1409-1416.

48 Christie RV, Meakins JC. The intrapleural pressure in congestive heart failure and its clinical significance. $J$ Clin Invest 1934; 13: 323-345.

49 Evans SA, Watson L, Cowley AJ, et al. Static lung compliance in chronic heart failure: relation with dyspnoea and exercise capacity. Thorax 1995; 50: 245-248.

50 Saxton GA, Rabinowitz M, Dexter L, et al. The relationship of pulmonary compliance to pulmonary vascular pressures in patients with heart disease. J Clin Invest 1956; 35: 611-618.

51 Frank NR, Lyons HA, Siebens AA, et al. Pulmonary compliance in patients with cardiac disease. Am J Med 1957; 22: $516-523$.

52 Ries AL, Gregoratos G, Friedman PJ, et al. Pulmonary function tests in the detection of left heart failure: correlation with pulmonary artery wedge pressure. Respiration 1986; 49: 241-250.

53 Duguet A, Tantucci C, Lozinguez O, et al. Expiratory flow limitation as a determinant of orthopnea in acute left heart failure. J Am Coll Cardiol 2000; 35: 690-700.

54 Cabanes LR, Weber SN, Matran R, et al. Bronchial hyperresponsiveness to methacholine in patients with impaired left ventricular function. N Engl J Med 1989; 320: 1317-1322. 
Light RW, George RB. Serial pulmonary function in patients with acute heart failure. Arch Intern Med 1983; 143: 429-433.

Guazzi M, Agostoni P, Matturri M, et al. Pulmonary function, cardiac function, and exercise capacity in a follow-up of patients with congestive heart failure treated with carvedilol. Am Heart J 1999; 138: 460-467.

Drexler H, Riede U, Munzel T, et al. Alterations of skeletal muscle in chronic heart failure. Circulation 1992; 85: 1751-1759.

D’Arsigny C, Webb KA, Raj S, et al. Ventilatory constraints contribute to exercise limitation and dyspnea in stable congestive heart failure. Am J Respir Crit Care Med 1999; 159: A418.

Agostoni PG, Marenzi GC, Sganzerla P, et al. Lung-heart interaction as a substrate for the improvement in exercise capacity after body fluid volume depletion in moderate congestive heart failure. Am J Cardiol 1995; 76: 793-798.

Papazachou O, Anastasiou-Nana M, Sakellariou D, et al. Pulmonary function at peak exercise in patients with chronic heart failure. Int J Cardiol 2007; 118: 28-35.

Dall'Ago P, Chiappa GR, Guths $\mathrm{H}$, et al. Inspiratory muscle training in patients with heart failure and inspiratory muscle weakness: a randomized trial. J Am Coll Cardiol 2006; 47: 757-763.

McConnell AK, Lomax M. The influence of inspiratory muscle work history and specific inspiratory muscle training upon human limb muscle fatigue. J Physiol 2006; 577: 445-457.

Uren NG, Davies SW, Jordan SL, et al. Inhaled bronchodilators increase maximum oxygen consumption in chronic left ventricular failure. Eur Heart J 1993; 14: 744-750. oxygenation and blood volume during high-intensity exercise in chronic heart failure. Am J Physiol Heart Circ Physiol 2008; 294: H2465-H2472.

Nanas S, Nanas J, Papazachou O, et al. Resting lung function and hemodynamic parameters as predictors of exercise capacity in patients with chronic heart failure. Chest 2003; 123: 1386-1393.

Sullivan MJ, Higginbotham MB, Cobb FR. Increased exercise ventilation in patients with chronic heart failure: intact ventilatory control despite hemodynamic and pulmonary abnormalities. Circulation 1988; 77: 552-559.

Wada $\mathrm{O}$, Asanoi $\mathrm{H}$, Miyagi $\mathrm{K}$, et al. Importance of abnormal lung perfusion in excessive exercise ventilation in chronic heart failure. Am Heart J 1993; 125: 790-798. functional capacity and hemodynamics. Am J Cardiol 1992; 70: 622-628.

Clark AL, Coats AJ. Exercise hyperventilation chronic congestive heart failure and its relation to functional capacity and hemodynamics. Am J Cardiol 1993; 71: 1007-1008.

Clark AL, Coats AJ. Usefulness of arterial blood gas estimations during exercise in patients with chronic heart failure. Br Heart I 1994; 71: 528-530.

Puri S, Baker BL, Dutka DP, et al. Reduced alveolar-capillary membrane diffusing capacity in chronic heart failure. Its pathophysiological relevance and relationship to exercise performance. Circulation 1995; 91: 2769-2774.

Guazzi M, Agostoni P, Bussotti M, et al. Impeded alveolar-capillary gas transfer with saline infusion in heart failure. Hypertension 1999; 34: 1202-1207.

Agostoni P, Cattadori G, Bianchi M, et al. Exercise-induced pulmonary edema in heart failure. Circulation 2003; 108: 2666-2671.

Paolillo S, Pellegrino R, Salvioni E, et al. Role of alveolar $\beta_{2}$-adrenergic receptors on lung fluid clearance and exercise ventilation in healthy humans. PloS One 2013; 8: e61877.

Robertson HT, Pellegrino R, Pini D, et al. Exercise response after rapid intravenous infusion of saline in healthy humans. J Appl Physiol (1985) 2004; 97: 697-703.

Agostoni PG, Guazzi M, Bussotti M, et al. Lack of improvement of lung diffusing capacity following fluid withdrawal by ultrafiltration in chronic heart failure. J Am Coll Cardiol 2000; 36: 1600-1604.

Kay JM, Edwards FR. Ultrastructure of the alveolar-capillary wall in mitral stenosis. J Pathol 1973; 111: 239-245.

Guazzi M, Pontone G, Brambilla R, et al. Alveolar-capillary membrane gas conductance: a novel prognostic indicator in chronic heart failure. Eur Heart J 2002; 23: 467-476.

Guazzi M, Palermo P, Pontone G, et al. Synergistic efficacy of enalapril and losartan on exercise performance and oxygen consumption at peak exercise in congestive heart failure. Am J Cardiol 1999; 84: 1038-1043.

Chugh SS, Chua TP, Coats AJ. Peripheral chemoreflex in chronic heart failure: friend and foe. Am Heart J 1996; 132: 900-904.

Sun SY, Wang W, Zucker IH, et al. Enhanced peripheral chemoreflex function in conscious rabbits with pacing-induced heart failure. J Appl Physiol 1999; 86: 1264-1272.

Sun SY, Wang W, Zucker IH, et al. Enhanced activity of carotid body chemoreceptors in rabbits with heart failure: role of nitric oxide. J Appl Physiol 1999; 86: 1273-1282.

Chua TP, Clark AL, Amadi AA, et al. Relation between chemosensitivity and the ventilatory response to exercise in chronic heart failure. J Am Coll Cardiol 1996; 27: 650-657.

Chua TP, Ponikowski P, Webb-Peploe K, et al. Clinical characteristics of chronic heart failure patients with an augmented peripheral chemoreflex. Eur Heart J 1997; 18: 480-486.

Weber KT, Kinasewitz GT, Janicki JS, et al. Oxygen utilization and ventilation during exercise in patients with chronic cardiac failure. Circulation 1982; 65: 1213-1223.

Franciosa JA, Leddy CL, Wilen M, et al. Relation between hemodynamic and ventilatory responses in determining exercise capacity in severe congestive heart failure. Am J Cardiol 1984; 53: 127-134.

Chua TP, Ponikowski P, Harrington D, et al. Clinical correlates and prognostic significance of the ventilatory response to exercise in chronic heart failure. J Am Coll Cardiol 1997; 29: 1585-1590.

Johnson RL Jr. Gas exchange efficiency in congestive heart failure II. Circulation 2001; 103: 916-918.

Ponikowski P, Francis DP, Piepoli MF, et al. Enhanced ventilatory response to exercise in patients with chronic heart failure and preserved exercise tolerance: marker of abnormal cardiorespiratory reflex control and predictor of poor prognosis. Circulation 2001; 103: 967-972.

Piepoli M, Clark AL, Volterrani M, et al. Contribution of muscle afferents to the hemodynamic, autonomic, and ventilatory responses to exercise in patients with chronic heart failure: effects of physical training. Circulation 1996; 93: 940-952.

Anker SD, Steinborn W, Strassburg S. Cardiac cachexia. Ann Med 2004; 36: 518-529. 

191-201.

93 Nicoletti I, Cicoira M, Zanolla L, et al. Skeletal muscle abnormalities in chronic heart failure patients: relation to exercise capacity and therapeutic implications. Congest Heart Fail 2003; 9: 148-154.

94 Minotti JR, Pillay P, Oka R, et al. Skeletal muscle size: relationship to muscle function in heart failure. J Appl Physiol 1993; 75: 373-381.

95 Nilsson KR, Duscha BD, Hranitzky PM, et al. Chronic heart failure and exercise intolerance: the hemodynamic paradox. Curr Cardiol Rev 2008; 4: 92-100.

96 Schaufelberger M, Eriksson BO, Grimby G, et al. Skeletal muscle alterations in patients with chronic heart failure. Eur Heart J 1997; 18: 971-980.

97 Sullivan MJ, Green HJ, Cobb FR. Skeletal muscle biochemistry and histology in ambulatory patients with long-term heart failure. Circulation 1990; 81: 518-527.

98 Lipkin DP, Jones DA, Round JM, et al. Abnormalities of skeletal muscle in patients with chronic heart failure. Int J Cardiol 1988; 18: 187-195.

99 Massie BM, Conway M, Rajagopalan B, et al. Skeletal muscle metabolism during exercise under ischemic conditions in congestive heart failure. Evidence for abnormalities unrelated to blood flow. Circulation 1988; 78: 320-326.

100 Massie B, Conway M, Yonge R, et al. Skeletal muscle metabolism in patients with congestive heart failure: relation to clinical severity and blood flow. Circulation 1987; 76: 1009-1019.

101 Anker SD, Ponikowski PP, Clark AL, et al. Cytokines and neurohormones relating to body composition alterations in the wasting syndrome of chronic heart failure. Eur Heart J 1999; 20: 683-693.

102 Hambrecht R, Schulze PC, Gielen S, et al. Reduction of insulin-like growth factor-I expression in the skeletal muscle of noncachectic patients with chronic heart failure. J Am Coll Cardiol 2002; 39: 1175-1181.

103 Niebauer J, Pflaum CD, Clark AL, et al. Deficient insulin-like growth factor I in chronic heart failure predicts altered body composition, anabolic deficiency, cytokine and neurohormonal activation. J Am Coll Cardiol 1998; 32: 393-397.

104 Volterrani M, Clark AL, Ludman PF, et al. Predictors of exercise capacity in chronic heart failure. Eur Heart J 1994; 15: 801-809.

105 Wilson JR, Mancini DM, Dunkman WB. Exertional fatigue due to skeletal muscle dysfunction in patients with heart failure. Circulation 1993; 87: 470-475.

106 Duscha BD, Annex BH, Green HJ, et al. Deconditioning fails to explain peripheral skeletal muscle alterations in men with chronic heart failure. J Am Coll Cardiol 2002; 39: 1170-1174.

107 Vescovo G, Serafini F, Facchin L, et al. Specific changes in skeletal muscle myosin heavy chain composition in cardiac failure: differences compared with disuse atrophy as assessed on microbiopsies by high resolution electrophoresis. Heart 1996; 76: 337-343.

108 Adreani CM, Hill JM, Kaufman MP. Responses of group III and IV muscle afferents to dynamic exercise. J Appl Physiol 1997; 82: 1811-1817.

109 Piepoli MF, Kaczmarek A, Francis DP, et al. Reduced peripheral skeletal muscle mass and abnormal reflex physiology in chronic heart failure. Circulation 2006; 114: 126-134.

110 Ponikowski PP, Chua TP, Francis DP, et al. Muscle ergoreceptor overactivity reflects deterioration in clinical status and cardiorespiratory reflex control in chronic heart failure. Circulation 2001; 104: 2324-2330.

111 Scott AC, Francis DP, Davies LC, et al. Contribution of skeletal muscle 'ergoreceptors' in the human leg to respiratory control in chronic heart failure. J Physiol 2000; 529 Pt 3: 863-870.

112 Coats AJ, Adamopoulos S, Radaelli A, et al. Controlled trial of physical training in chronic heart failure. Exercise performance, hemodynamics, ventilation, and autonomic function. Circulation 1992; 85: 2119-2131.

113 Hughes PD, Polkey MI, Harrus ML, et al. Diaphragm strength in chronic heart failure. Am J Respir Crit Care Med 1999; 160: 529-534.

114 Granton JT, Naughton MT, Benard DC, et al. CPAP improves inspiratory muscle strength in patients with heart failure and central sleep apnea. Am J Respir Crit Care Med 1996; 153: 277-282.

115 Daganou M, Dimopoulou I, Alivizatos PA, et al. Pulmonary function and respiratory muscle strength in chronic heart failure: comparison between ischaemic and idiopathic dilated cardiomyopathy. Heart 1999; 81: 618-620.

116 Hammond MD, Bauer KA, Sharp JT, et al. Respiratory muscle strength in congestive heart failure. Chest 1990; 98: 1091-1094.

117 McParland C, Krishnan B, Wang Y, et al. Inspiratory muscle weakness and dyspnea in chronic heart failure. Am Rev Respir Dis 1992; 146: 467-472.

118 Ambrosino N, Opasich C, Crotti P, et al. Breathing pattern, ventilatory drive and respiratory muscle strength in patients with chronic heart failure. Eur Respir J 1994; 7: 17-22.

119 Nishimura Y, Maeda H, Tanaka K, et al. Respiratory muscle strength and hemodynamics in chronic heart failure. Chest 1994; 105: 355-359.

120 Evans SA, Watson L, Hawkins M, et al. Respiratory muscle strength in chronic heart failure. Thorax 1995; 50: $625-628$.

121 Kasahara Y, Izawa KP, Watanabe S, et al. The relation of respiratory muscle strength to disease severity and abnormal ventilation during exercise in chronic heart failure patients. Res Cardiovasc Med 2015; 4: e28944.

122 Frankenstein L, Meyer FJ, Sigg C, et al. Is serial determination of inspiratory muscle strength a useful prognostic marker in chronic heart failure? Eur J Cardiovasc Prev Rehabil 2008; 15: 156-161.

123 Callegaro CC, Martinez D, Ribeiro PA, et al. Augmented peripheral chemoreflex in patients with heart failure and inspiratory muscle weakness. Respir Physiol Neurobiol 2010; 171: 31-35.

124 St Croix CM, Morgan BJ, Wetter TJ, et al. Fatiguing inspiratory muscle work causes reflex sympathetic activation in humans. J Physiol 2000; 529 Pt 2: 493-504.

125 Mancini DM, Henson D, LaManca J, et al. Respiratory muscle function and dyspnea in patients with chronic congestive heart failure. Circulation 1992; 86: 909-918.

126 Musch TI. Elevated diaphragmatic blood flow during submaximal exercise in rats with chronic heart failure. Am J Physiol 1993; 265: H1721-H1726.

127 Johnson BD, Beck KC, Olson LJ, et al. Ventilatory constraints during exercise in patients with chronic heart failure. Chest 2000; 117: 321-332. 
J Appl Physiol 1989; 66: 2539-2545.

135 Tikunov $\mathrm{B}$, Levine S, Mancini D. Chronic congestive heart failure elicits adaptations of endurance exercise in diaphragmatic muscle. Circulation 1997; 95: 910-916.

136 Lindsay DC, Lovegrove CA, Dunn MJ, et al. Histological abnormalities of muscle from limb, thorax and diaphragm in chronic heart failure. Eur Heart J 1996; 17: 1239-1250.

137 Howell S, Maarek JM, Fournier M, et al. Congestive heart failure: differential adaptation of the diaphragm and latissimus dorsi. J Appl Physiol 1995; 79: 389-397.

138 Mitch WE, Goldberg AL. Mechanisms of muscle wasting. The role of the ubiquitin-proteasome pathway. $N$ Engl J Med 1996; 335: 1897-1905.

139 Mancini DM, Ferraro N, Nazzaro D, et al. Respiratory muscle deoxygenation during exercise in patients with heart failure demonstrated with near-infrared spectroscopy. J Am Coll Cardiol 1991; 18: 492-498.

140 Terakado S, Takeuchi T, Miura T, et al. Early occurrence of respiratory muscle deoxygenation assessed by near-infrared spectroscopy during leg exercise in patients with chronic heart failure. Jpn Circ J 1999; 63: 97-103.

141 Mancini DM, Henson D, La Manca J, et al. Benefit of selective respiratory muscle training on exercise capacity in patients with chronic congestive heart failure. Circulation 1995; 91: 320-329.

142 Johnson PH, Cowley AJ, Kinnear WJ. A randomized controlled trial of inspiratory muscle training in stable chronic heart failure. Eur Heart J 1998; 19: 1249-1253.

143 Winkelmann ER, Chiappa GR, Lima CO, et al. Addition of inspiratory muscle training to aerobic training improves cardiorespiratory responses to exercise in patients with heart failure and inspiratory muscle weakness. Am Heart J 2009; 158: 768-767. 